\title{
Calcário líquido e calcário convencional na correção da acidez do solo
}

\author{
Amauri Bambolim ${ }^{1}$, Gustavo Caione ${ }^{1}$, Naiara Fernanda Souza ${ }^{1}$, Getúlio de Freitas Seben \\ Junior', Guilherme Ferreira Ferbonink ${ }^{1}$ \\ ${ }^{1}$ Universidade do Estado de Mato Grosso - UNEMAT, Alta Floresta, MT, Brasil. E-mail: amauribambolim@ outlook.com, \\ gcaione@unemat.br,nayara_fernandha@hotmail.com, getulioseben@unemat.br, ferbonink@hotmail.com
}

Recebido: 17/08/2015; Aceito: 04/10/2015

\section{RESUMO}

A acidez pode alterar a disponibilidade dos nutrientes no solo. Objetivou-se com o presente trabalho avaliar o efeito da aplicação de calcário líquido e calcário convencional na correção da acidez de um Latossolo Vermelho-Amarelo distrófico do Cerrado. O delineamento experimental utilizado foi inteiramente casualizado, com três repetições. As doses de calcário líquido aplicadas foram equivalentes a 5;10;15 e $20 \mathrm{~L} \mathrm{ha}^{-1}$ e as doses de calcário convencional utilizadas foram equivalentes a 1,$0 ; 1,5 ; 2,0$ e $2,5 \mathrm{t} \mathrm{ha}^{-1}$. Após a aplicação dos corretivos de acidez, o solo foi acondicionado em recipientes com capacidade para $0,4 \mathrm{dm}^{3}$ com umidade próxima a capacidade de campo. Aos 70 dias após a aplicação dos corretivos foram mensurados o $\mathrm{pH}$ do solo, teores de potássio $\left(\mathrm{K}^{+}\right)$, cálcio $\left(\mathrm{Ca}^{2+}\right)$, magnésio $\left(\mathrm{Mg}^{2+}\right)$, alumínio trocável $\left(\mathrm{Al}^{3+}\right)$, acidez potencial $(\mathrm{H}+\mathrm{Al})$ e calcularam-se a capacidade de troca de cátions (CTC), saturação de bases (V\%) e saturação de alumínio (m\%). O calcário líquido não corrigiu a acidez do solo e não elevou a saturação por bases, apenas elevou os teores de Ca no solo. A aplicação de doses de calcário convencional proporcionou correção da acidez do solo e elevação da saturação de bases.

Palavras-chave: calagem, $\mathrm{pH}$ do solo, química do solo, fertilidade do solo.

\section{Liquid lime and conventional lime on correction of soil acidity}

\begin{abstract}
The acidity can change the availability of nutrients in the soil. The objective of the present study was to evaluate the effect of application of liquid lime and conventional lime on the acidity correction of a Red-Yellow Latosol of the Brazilian Cerrado. The experimental design was completely randomized, with three replications. The applied liquid lime rates were equivalent to $5 ; 10 ; 15$ and $20 \mathrm{~L} \mathrm{ha}^{-1}$ and conventional lime rate used was equivalent to 1.0; $1.5 ; 2.0$ to $2.5 \mathrm{t} \mathrm{ha}^{-1}$. After liming, the soil was packed in containers with capacity of $0.4 \mathrm{dm}^{3}$ and humidity close to field capacity. At 70 days after liming were measured soil $\mathrm{pH}$, potassium $\left(\mathrm{K}^{+}\right)$, calcium $\left(\mathrm{Ca}^{2+}\right)$, magnesium $\left(\mathrm{Mg}^{2+}\right)$, exchangeable aluminum $\left(\mathrm{Al}^{3+}\right)$, potential acidity $(\mathrm{H}+\mathrm{Al})$ and calculated to cation exchange capacity (CEC), base saturation $(\mathrm{V} \%)$ and aluminum saturation $(\mathrm{m} \%)$. The liquid lime did not correct soil acidity and did not raise the soil base saturation, just raised the Ca concentration in the soil. The application of conventional lime rates provided soil acidity correction and increase in soil base saturation.
\end{abstract}

Keywords: liming; pH of the soil; Chemical soil; soil fertility. 


\section{Introdução}

A acidez ou a alcalinidade excessiva do solo são os fatores que mais afetam a disponibilidade dos nutrientes às plantas. Portanto, a determinação da acidez do solo antes do preparo e cultivo do solo torna-se de extrema importância para o sucesso dos sistemas de produção agrícola (CAIRES, 2013). A acidez no solo ocorre por vários fatores como a mineralogia do solo, a intensa lixiviação e/ou remoção de bases pelas culturas, as chuvas ácidas, o uso de fertilizantes nitrogenados com ação acidificante e a decomposição da matéria orgânica, que libera ácidos orgânicos e inorgânicos (OLIVEIRA et al., 2005).

O ácido carbônico, resultante da combinação do óxido carbônico com a água, é o ácido encontrado em maior abundância no solo. No entanto, por ser um ácido fraco não pode ser responsabilizado pelos baixos valores de pH do solo. Ácidos inorgânicos, como ácido sulfúrico e ácido nítrico e alguns ácidos orgânicos fortes, são relevantes supridores de íons $\mathrm{H}^{+}$à solução do solo (OLIVEIRA et al., 2005).

A adequada correção da acidez do solo é muito importante para a sustentabilidade do uso agrícola do solo, pois um solo ácido compromete o desenvolvimento e a produtividade das culturas. Assim, a calagem tem se destacado como a prática mais utilizada na agricultura para adequar as propriedades químicas do solo às necessidades das culturas (OLIVEIRA et al., 2010). Poucas práticas agrícolas dão retornos tão elevados como a correção da acidez do solo, no que diz respeito ao aumento da produtividade das culturas. De fato, a calagem se faz necessária para elevar o índice de saturação por bases (V\%) a valores superior a $60 \%$ e para manter o $\mathrm{pH}$ do solo acima de 5,5, o que favorece a neutralização do alumínio trocável $\left(\mathrm{Al}^{3+}\right)$ e eleva a disponibilidade das bases trocáveis no solo (ALCARDE, 2005).

Atualmente, algumas empresas comercializam corretivos de solo na forma líquida e, de acordo com as mesmas, o resultado é mais rápido e duradouro, em relação ao calcário em pó. $\mathrm{O}$ produto tem como objetivo corrigir a acidez do solo, fornecer $\mathrm{Ca}^{2+}$ e $\mathrm{Mg}^{2+}$, e neutralizar os efeitos fitotóxicos do $\mathrm{Al}^{3+}$ no solo (BURG et al. 2013).

Neste sentido, algumas pesquisas foram realizadas para avaliar a eficiência de materiais corretivos da acidez dos solos como o uso de escória de siderurgia, em relação ao calcário convencional e seus efeitos nas propriedades químicas do solo (PRADO; FERNANDES, 2000), crescimento de plantas (ROCHA et al., 2008), entre outros. Um aspecto importante é que o uso do produto líquido chamado de calcário, ainda não tem sua eficácia comprovada, pois poucas são as informações encontradas com relação ao seu uso em comparação com o calcário convencional.
Este estudo teve como objetivo avaliar o efeito da aplicação de calcário líquido e calcário convencional na correção da acidez de um Latossolo Vermelho-Amarelo do Cerrado.

\section{Material e Métodos}

O trabalho foi realizado durante os meses de outubro a dezembro de 2014 no Laboratório de Solos da Universidade do Estado de Mato Grosso - UNEMAT, Campus Universitário de Alta Floresta.

O solo utilizado foi classificado como Latossolo Vermelho-Amarelo distrófico (EMBRAPA, 2013). As amostras de solos foram coletadas na camada de 0,40$0,60 \mathrm{~m}$ de profundidade. A granulometria do solo indicou $392 \mathrm{~g} \mathrm{~kg}^{-1}$ de areia, $330 \mathrm{~g} \mathrm{~kg}^{-1}$ de silte e $278 \mathrm{~g}$ $\mathrm{kg}^{-1}$ de argila, determinada pelo método da pipeta (EMBRAPA, 2009). As propriedades químicas do solo foram determinadas conforme metodologia proposta pela EMBRAPA (2009), e os resultados da análise química resultou nos seguintes valores: $\mathrm{pH}$ em água de 5,5;0,13 $\mathrm{cmol}_{\mathrm{c}} \mathrm{dm}^{-3}$ de Ca; 0,07 $\mathrm{cmol}_{\mathrm{c}} \mathrm{dm}^{-3} \mathrm{de} \mathrm{Mg}$; $0,05 \mathrm{cmol}_{\mathrm{c}} \mathrm{dm}^{-3}$ de $\mathrm{K} ; 2,3 \mathrm{cmol}_{\mathrm{c}} \mathrm{dm}^{-3}$ de $\mathrm{H}+\mathrm{Al} ; 2,55$ $\mathrm{cmol}_{\mathrm{c}} \mathrm{dm}^{-3}$ de CTC e $10 \%$ de saturação por bases.

$\mathrm{O}$ experimento foi instalado seguindo o delineamento inteiramente casualizado, com três repetições. Os tratamentos foram compostos por quatro doses de calcário líquido conforme recomendação do fabricante: $5 ; 10 ; 15$ e $20 \mathrm{~L} \mathrm{ha}^{-1}$ e quatro doses de calcário convencional: $1 ; 1,5 ; 2,0$ e $2,5 \mathrm{t} \mathrm{ha}^{-1}$, objetivando elevar a saturação por bases para $45 \%$, $65 \%, 80 \%$ e $98 \%$, respectivamente. O solo foi homogeneizado com as doses de calcário, acondicionado em recipientes com capacidade para 0,4 $\mathrm{dm}^{3}$ e incubado por 70 dias com umidade próximo à capacidade de campo. O calcário líquido utilizado no experimento continha, segundo informações do fabricante, $46,7 \%$ de carbonato de cálcio $\left(\mathrm{CaCO}_{3}\right), 11 \%$ de óxido de magnésio $(\mathrm{MgO}), 16,5 \%$ de $\mathrm{Ca}$ e $23 \%$ de óxido de cálcio $(\mathrm{CaO})$. O calcário convencional utilizado foi o calcítico, com 36,57\% de $\mathrm{CaO}, 2,65 \%$ de $\mathrm{MgO}$ e PRNT de $90 \%$.

Após o período de incubação, o solo foi seco e passado em peneira com abertura de malha de 2,00 mm, terra final seca ao ar (TFSA). Em seguida, foram feitas as análises para determinação do $\mathrm{pH}$, teores de $\mathrm{Ca}, \mathrm{Mg}$, $\mathrm{K}, \mathrm{H}+\mathrm{Al}$ e $\mathrm{Al}$ e os cálculos da CTC, V\% e $\mathrm{m} \%$, seguindo a metodologia proposta pela Embrapa (2009).

Os dados foram submetidos à análise de variância pelo teste $\mathrm{F}(P=0,05)$ e análise de regressão, utilizando o programa estatístico SISVAR (FERREIRA, 2011). Na análise de regressão, os coeficientes dos componentes de cada modelo foram testados, escolhendo-se os modelos significativos com maior coeficiente de determinação $\left(\mathrm{R}^{2}\right)$. 


\section{Resultados e Discussão}

\section{Efeito do uso de calcário líquido nas propriedades} químicas do solo

A aplicação de doses de calcário líquido não foi eficiente para elevar o valor do $\mathrm{pH}$ do solo, apresentando valor médio de $\mathrm{pH}$ de 5,7 $(P>0,05)$. Este resultado reporta que a concentração de $\mathrm{OH}^{-}$contida no produto é muito inferior à sua capacidade de neutralizar os íons $\mathrm{H}^{+}$. Resultados semelhantes foram reportados por Burg et al. (2013), os quais constataram que a aplicação de calcário líquido não neutralizou a acidez do solo, portanto não recomendamos a aplicação do calcário líquido como corretivo de acidez do solo.

A aplicação de calcário líquido não afetou $(P>0,05)$ a maioria das propriedades químicas do solo. Os teores médios de $\mathrm{Al}^{3+}, \mathrm{H}+\mathrm{Al}, \mathrm{Mg}$ e $\mathrm{K}$ do solo foram 0,34; 2,33; $\mathrm{Mg} 0,06$ e $0,06 \mathrm{cmol}_{\mathrm{c}} \mathrm{dm}^{-3}$, respectivamente. A CTC do solo foi de $2,65 \mathrm{cmol}_{\mathrm{c}} \mathrm{dm}^{-3}$ e a saturação de bases (V\%) e alumínio ( $\mathrm{m} \%$ ) foram de $10,5 \%$ e $53 \%$, respectivamente. Burg et al. (2013) também verificaram que o teor de $\mathrm{Mg}$ e saturação de bases não foram afetados pela aplicação de calcário líquido. Este resultado demonstra que nestas doses aqui testadas o produto não apresenta eficiência sobre estes atributos químicos do solo.

A aplicação de doses de calcário líquido resultou no aumento linear dos teores de Ca do solo (Figura 1). No presente estudo o incremento no teor de Ca pode estar associado às maiores doses testadas, chegando a $20 \mathrm{~L}$ ha-1 e como o Ca está contido na composição química do produto, houve este incremento.

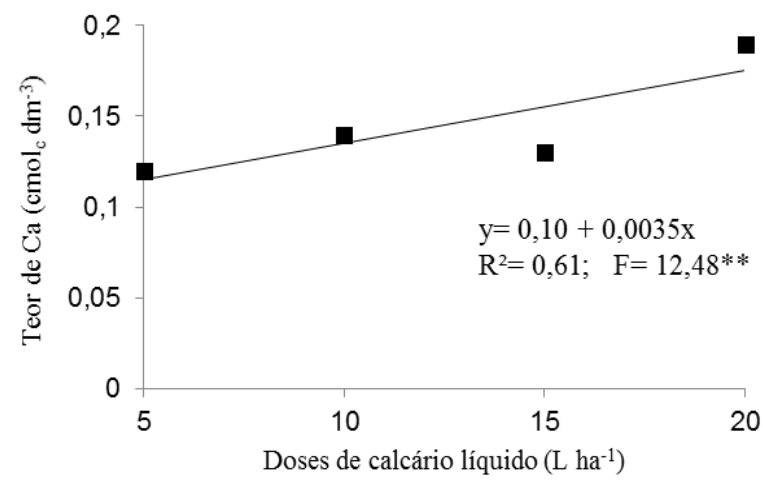

Figura 1. Teores de cálcio no solo após 70 dias da aplicação do calcário líquido.

\section{Efeito do uso de calcário convencional nas propriedades químicas do solo}

A aplicação de calcário convencional foi eficaz na correção da acidez do solo, resultando no aumento do pH (Figura 2) e, consequentemente, na redução da acidez potencial (H+Al) (Figura 3), o teor e a saturação por alumínio, no entanto, para estes resultados não houve efeito significativo para os modelos testados (linear e quadrático). Estes resultados estão de acordo com Caires et al. (2002), Anjos et al. (2011), Natale et al. (2007) e Kaminski et al. (2005) que verificaram a eficácia da aplicação de calcário na correção da acidez do solo e na redução dos teores de $\mathrm{Al}^{3+}$, acidez ativa $\left(\mathrm{H}^{+}\right)$, acidez potencial $(\mathrm{H}+\mathrm{Al})$ e saturação por alumínio.

A aplicação de doses de calcário convencional resultou em aumento linear no teor de cálcio (Figura 4), porém, não apresentou alterações nos teores de magnésio, provavelmente por se tratar de um calcário calcítico com baixos teores de magnésio.

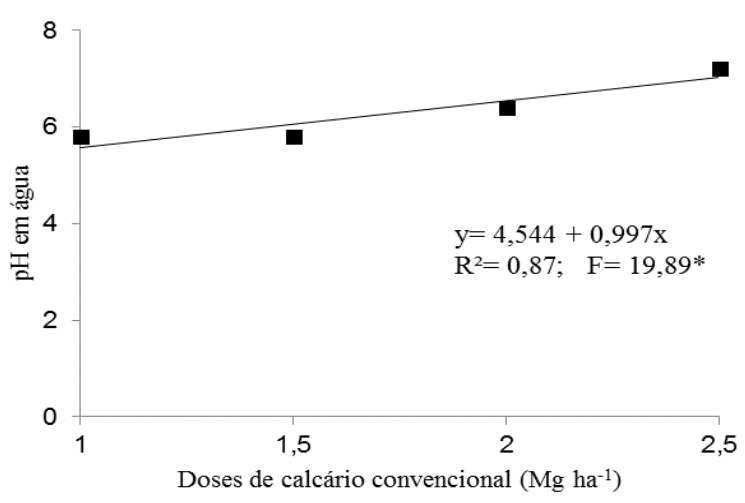

Figura 2. Valor de pH do solo após 70 dias da aplicação do calcário convencional.

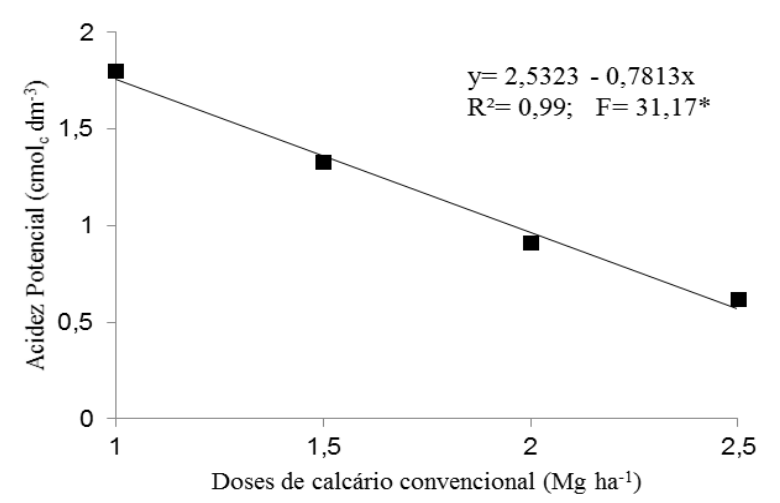

Figura 3. Valor de acidez potencial $(\mathrm{H}+\mathrm{Al})$ do solo após 70 dias da aplicação do calcário convencional.

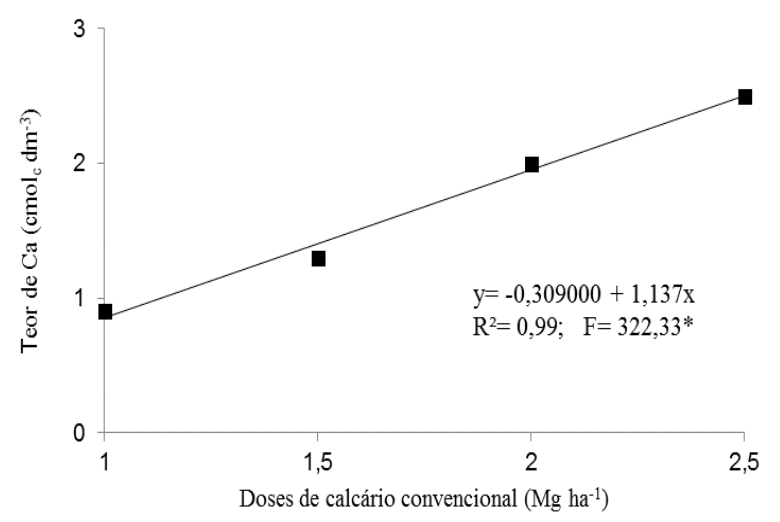

Figura 4. Teores de cálcio no solo após 70 dias da aplicação do calcário convencional. 
Houve aumento linear na saturação por bases do solo em função da aplicação de doses de calcário convencional (Figura 5). Este resultado também foi verificado por Ciotta et al. (2004) utilizando calcário calcítico. Camargo et al. (1997) utilizando doses de 0, 1, 2 e $4 \mathrm{Mg} \mathrm{ha}^{-1}$ de calcário calcítico também reportou aumento na saturação por bases.

A CTC apresentou aumento linear com a aplicação de doses de calcário convencional (Figura 6). Os valores aumentaram de 2,39 $\mathrm{cmol}_{\mathrm{c}} \mathrm{dm}^{-3}$ no tratamento controle se calagem para $3,36 \mathrm{cmol}_{\mathrm{c}} \mathrm{dm}^{-3}$ na maior dose aplicada (2,5 $\left.\mathrm{Mg} \mathrm{ha}^{-1}\right)$. Resultados semelhantes também foram reportados por Alleoni et al. (2005) em experimento com doses 2,0, 4,9 e 7,8 $\mathrm{t} \mathrm{ha}^{-1}$, em que verificaram aumento na CTC do solo.

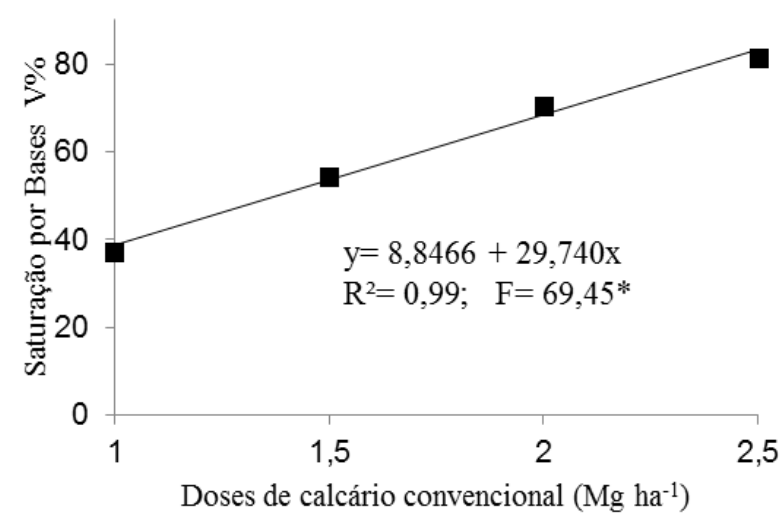

Figura 5. Saturação por bases no solo após 70 dias da aplicação do calcário convencional.

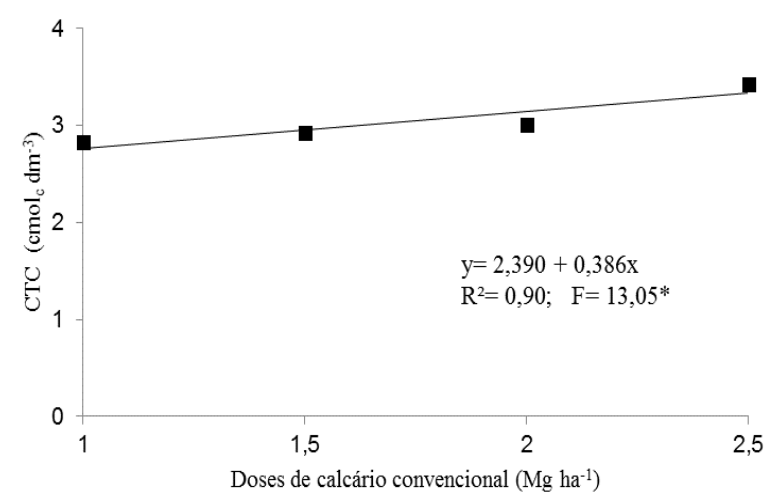

Figura 6. Capacidade de troca de cátions (CTC) do solo após 70 dias da aplicação do calcário convencional.

O uso da calagem é essencial na agricultura moderna, trazendo benefícios para o solo (ANJOS et al., 2011), crescimento de plantas (ROCHA et al., 2008) e aumento na produtividade (CAIRES et al., 2003), tornando de grande importância o seu uso nos solos ácidos brasileiros. Porém, o calcário líquido não satisfaz as expectativas de um corretivo de acidez podendo apenas ser utilizado, eventualmente, como fonte de $\mathrm{Ca}$ para as plantas.

\section{Conclusões}

As doses de calcário líquido não alteraram o pH e saturação por bases do solo e, portanto, não possui características de um corretivo de acidez solo nas condições experimentais utilizadas.

O calcário convencional corrigiu a acidez do solo e elevou a saturação por bases do solo, confirmando seus efeitos de correção da acidez do solo e de suprimento de cálcio e magnésio.

\section{Referências Bibliográficas}

ALCARDE, J. C. Corretivos da acidez dos solos. São PauloSP: ANDA, 2005.

ALlEONI, L. R. F.; CAMBRI, M. A.; CAIRES, E. F. Atributos químico de um Latossolo de cerrado sob plantio direto, de acordo com doses e formas de aplicação de calcário. Revista Brasileira de Ciência do Solo, Viçosa-MG, v. 29, n. 3, p. 923-934, 2005.

ANJOS, J. L.; SOBRAL, L. F.; LIMA-JUNIOR, M. A. Efeito da calagem em atributos químicos do solo e na produção da laranjeira. Revista Brasileira de Engenharia Agrícola e Ambiental, Campina Grande-PB, v. 15, n. 11, p. 1138-1142, 2011.

BURG, G.; DEAK, E.; SCHMIDT, M. R.; BEUTLER, A. N.; GALON, L.; GIACOMELI, R. Efeito do calcário líquido nas características químicas do solo. Revista Salão de Pesquisa, Itaqui-RS, v. 5 n. 2, p. 93, 2013.

CAIRES, E. F.; BARTH, G.; GARBUIO, F. J.; KUSMAN, M. $\mathrm{T}$, Correção da acidez do solo, crescimento radicular e nutrição do milho de acordo com a calagem na superfície em sistema plantio direto. Revista Brasileira de Ciência do Solo, Viçosa-MG, v. 26, n. 4, p. 1011-1022, 2002.

CAIRES, E. F. Correção da acidez do solo em sistemas plantio direto. Piracicaba-SP: International Plant Nutrition Istitute (INPI), 2013. 13 p. (Informações agronômicas, n. 141).

CAIRES, E. F.; FERRARI, R. A.; MORGANO, M. A. Produtividade e qualidade da soja em função da calagem na superfície em semeadura direta. Bragantia, Campinas-SP, v. 62, n. 2, p. 283-290, 2003.

CAMARGO, O. A.; CASTRO, O. M.; VIEIRA, S. R.; QUAGGIO, J. A. Alteração de atributos químicos do horizonte superficial de um Latossolo e um Podzólico com a calagem. Scientia Agricola, Piracicaba-SP, v. 54, n. 1-2, p. 675-688, 1997.

CIOTTA, M. N.; BAYER, C.; ERNANI, P. R.; FONTOURA, S. M. V.; WOBETO, C.; ALBUQUERQUE, J. A. Manejo da calagem e os componentes da acidez de Latossolo Bruno em plantio direto. Revista Brasileira de Ciência do Solo, Viçosa-MG, v. 28, n. 2, p. 317-326, 2004.

EMBRAPA - Embrapa Solos. Manual de análises químicas de solos, plantas e fertilizantes. Brasília-DF: Embrapa Informação Tecnológica; Brasília-DF: Embrapa Solos, 2009. $627 \mathrm{p}$. 
FERREIRA, D. F. Sisvar: a computer statistical analysis system. Ciência e Agrotecnologia, Lavras-MG, v. 35, n. 6, p. 1039-1042, 2011.

KAMINSKI, J.; SANTOS, D. R.; GATIBONI, L. C.; BRUNETO, G.; SILVA, L. S. Eficiência da calagem superficial e incorporada precedendo o sistema plantio direto em um Argissolo sob pastagem natural. Revista Brasileira de Ciência do Solo, Viçosa-MG, v. 29, n. 3, p. 573-580, 2005.

NATALE, W.; PRADO, R. M.; ROZANE, D. E.; ROMUALDO, L. M. Efeitos da calagem na fertilidade do solo e na nutrição e produtividade da goiabeira. Revista Brasileira de Ciência do Solo, Viçosa-MG, v. 31, n. 6, p. 1475-1485, 2007.

OLIVEIRA, C. M. R.; PASSOS, R. R.; ANDRADE, F. V.; REIS, E. F.; STURM, G. M.; SOUZA, R. B. Corretivo da acidez do solo e níveis de umidade no desenvolvimento da cana-de-açucar. Revista Brasileira de Ciências Agrárias, Recife-PE, v. 5, n. 1, p. 25-31, 2010.
OLIVEIRA, I. P.; COSTA, K. A. P.; SANTOS, K. J. G.; MOREIRA, F. P. Considerações sobre a acidez dos solos de cerrado. Revista Eletrônica Faculdade Montes Belos, Montes Belos-GO, v. 1, n. 1, p. 1-12, 2005.

PRADO, R. M.; FERNANDES, F. M. Escória de siderurgia e calcário na correção da acidez do solo cultivado com cana-deaçúcar em vaso. Scientia Agricola, Piracicaba-SP, v. 57, n. 4, p. 739-744, 2000.

ROCHA, J. B. O.; POZZA, A. A. A.; CARVALHO, J. G.; SILVA, C. A.; CURI, N. Efeito da calagem na nutrição mineral e no crescimento inicial do eucalipto a campo em Latossolo húmico da Zona da Mata (MG). Scientia Forestalis, Piracicaba-SP, v. 36, n. 80, p. 255-263, 2008. 